\title{
Metastatic Pancreatic Carcinoma
}

National Cancer Institute

\section{Source}

National Cancer Institute. Metastatic Pancreatic Carcinoma. NCI Thesaurus. Code C156069.

A carcinoma that arises from the pancreas and has metastasized to another anatomic site. 